\title{
A Game Approach to Assessing Learning Outcomes
}

\author{
David N. Prata, Patrick Letouze, Stefano Cerri, and Evandro Costa
}

\begin{abstract}
Persuasive technological strategies directed towards changing users' attitudes or behaviors have thus far been applied in commercial and health promotion contexts, but not for educational purposes. The main reason for this lack of research in educational settings can be attributed to an insufficient understanding of which attitudes or behaviors should be adopted through the evaluation of students' effective learning outcomes. In this study, we present an association between interpersonal conflict and positive learning and depicted the speaker's intention and the hearer's interpretation for cooperative and competitive player roles in light of game theory.
\end{abstract}

Index Terms - Computer-supported collaborative learning, flaming, insults, interpersonal conflict.

\section{INTRODUCTION}

During collaboration in computer-supported collaborative learning (CSCL), students engage in a wide variety of collaborative and learning behaviors, which impact each student's learning in a variety of ways [1]-[3]. Throughout CSCL tasks, interactions between students are recorded in protocols. The analysis can be time consuming due to the large amount of data that must be managed. Hence, an automatic coding procedure for coding dialogue acts is required.

Reference [4] recognized at least four general activities for the analysis of the interactive processes in collaborative learning dialogues: social, cognitive, affective, and meta-cognitive. [5], however, argues that it is inconceivable to dissociate cognitive tasks from social tasks because all cognitive tasks have a social component. In addition to these activities, other variables can be identified, for example, dialogue structure and sequence [6] and didactic-pedagogic issues [7].

Some researchers [8]-[10], have encouraged collaborative knowledge sharing. Reference [11] and [12] argued that social interaction is crucial to productive collaborative learning. Cognitive processes in collaboration, such as problem solving [13], are as important as social factors, such as motivating environments with positive affective relationships [14], [15].

Studies from the 1970s have demonstrated that conflict

Manuscript received July 17, 2014; revised October 8, 2014. This work was funded in part by NSF grant REC-043779 to "IERI: Learning-Oriented Dialogs in Cognitive Tutors: Toward a Scalable Solution to Performance Orientation."

David N. Prata and Patrick Letouze are with Federal University of Tocantins, CO 77.001-009, Brazil (e-mail: ddnprata@uft.edu.br).

Stefano Cerri is with Université Montpellier, CO 34000, France (e-mail: cerri@lirmm.fr).

Evandro Costa is with the Federal University of Tocantins, Palmas, CO 77.001-019, Brazil (e-mail: ebc.academico@gmail.com). and interaction promote cognitive development [16]-[20], and describe distinctions between conflict and content [21], consistent with Piaget's [22] discussion of the equilibration process.

Several studies have found that cognitive conflict and learning emerge from the process of collaboration, when students mutually engage to co-construct shared knowledge [1]-[3]. Additionally, other studies have provided evidence suggesting that cognitive conflict does not only occur in purely collaborative and consensus-based processes. For example, [23] and [24] provide evidence that conflicting ideas often lead to interpersonal conflict.

This study aimed to evaluate how social behavior can influence student's learning. Previous studies (e.g., [25]) have found insults to be associated with positive learning. In this study, we describe complementary findings for the role of insults in collaborative learning, depicting the speaker's intention and the hearer's interpretation for cooperative and competitive player roles in light of game theory.

\section{Player Roles in COLlaborative LEARNING}

Collaborative learning can be seen as a social game in which agents (players) are able to cooperate or compete in order to solve a problem. For game theory, the classic prisoner dilemma, the goal is to win goodness; competition means win-lose, cooperation means win-win, but there is also the awkward 'lose-lose' collaborative situation. The medium could be communication, negotiation, and/or mediation. We sought to investigate who was most likely to gain knowledge (the goal) in CSCL games by examining the roles of the person who cooperates or competes as well as the person who sends information or receives it, and the effects of communication, negotiation, and mediation on the knowledge-building process.

Based on the findings of [25] and [26], we have developed Fig. 1.

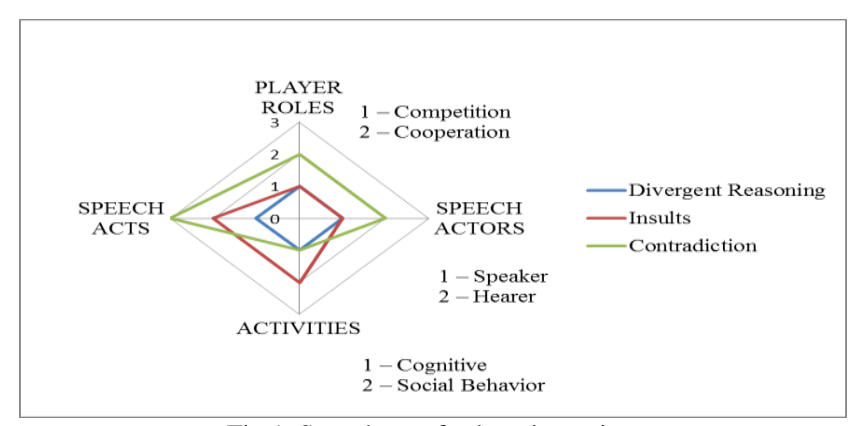

Fig.1. Speech acts for learning gains.

The analysis of a set of chat protocols using this coding scheme allowed us to identify speech acts [27] that correlated with learning gains for cooperative and competitive student player roles. These categories were qualified in terms of 
cognitive and social behavior activities in accordance with the coding scheme as follows: divergent reasoning, contradiction, and insults. The study was conducted using a fine-grained extension to the discourse analysis, making a distinction between the sender of the speech act (speaker) and the receiver of the speech act (hearer). Reference [26] addressed evidence that the cognitive process of cooperation is beneficial to collaborative learning for the hearer, as they could not find cooperative speech acts that correlated with learning gains for the speaker. However, the cognitive process of competition should be equally beneficial to the speaker, as they could not determine competitive speech acts that significantly correlated with leaning gains for the hearer.

Based on Piagetian theories for learning, the dialogue could and should evoke conflicting ideas. To engage in argumentation, the players must intend to learn from each other. When disputing their ideas, players intend to convince each other of their point of view. Therefore, the insult act is an intention of one student to persuade another student. Indeed, we can classify insult speech acts as part of the player role in competition.

\section{GAME THEORY AND DisPUTE RESOLUTION}

Game theory is a strategic decision-making paradigm studied primarily in economics, political sciences, psychology, as well as biology and logic — which study the interactions between agents pursuing their own self interests. Game theory also studies automated negotiation, as the negotiating parties can be characterized as self-interested. In game theory, the space of possible agent actions is frequently accepted to be sufficiently known by the agents. It turns out that the search space of strategies and interactions must be considered to have exponential growth, which means that the problem of finding an optimal strategy is, in general, computationally intractable [28]. Argumentation-based negotiation approaches aim to remove these limitations. In the negotiation game theory approach, the only feedback that can be provided by an agent is a counter-proposal. For argumentation negotiation, in addition to rejecting a proposal, an agent can offer a critique of the proposal, explaining why it is unacceptable. These new argumentations can lead to a whole new area of the negotiation space not worth exploring for the other agent.

During the argumentation-based negotiation process, agents can be convinced or persuaded to change their point of view. An example is the Adjusted Winner algorithm [29] that often leads to a win-win situation, in a similar manner to the Nash equilibrium [30]. Argumentation-based negotiation has been used in dispute resolution to denote participants' roles, (i.e., negotiator, mediator, conciliator, and arbitrator). Negotiation is a discussion among two or more individuals with the aim to reach a consensus. Mediation is a volunteer process, in which a third neutral party helps two or more persons in conflict to construct a mutually acceptable solution. Conciliation is an informal process in which a third party acts in an attempt to resolve any differences between parties. Arbitrage is a process in which a third neutral party, after reviewing the evidence, imposes a legally binding decision for both sides [31].

\section{CONFLICT AND FLAMING}

Conflict is an interactive process manifested in disagreement between members of a group (interpersonal conflict) that has been researched extensively over the last 30 years [32]. Conflict includes flaming, that is, hostile interaction via text-based computer-mediated communication [33]-[35]. Nevertheless, it remains unclear how conflict [36], [37] or flaming [38] should be defined.

One attribute that contributes to this controversy is the ambiguity in the conceptual definitions of message content versus message context [39]. According to [40], conflicts can be classified within tasks, processes, and relationships. Relationship conflicts ascend when the interactions involve affective components (e.g., tension). For [40], relationship conflict is significantly more negative in damaging group harmony.

Although we can detect conflict — including flaming — in both computer-mediated communication (CMC) and face-to-face-mediated channels [36], [37], researchers tend to consider flaming an online phenomenon [38]. Indeed, some investigations found that electronic communication allows people to write things online that they would seldom say in face-to-face situations, thereby generating flames [41]. Other investigations elicited the ambiguity surrounding communicative behavior (miscommunication) through the absence of visual and non-verbal cues [42], [43].

Flaming has also been characterized as an antisocial interaction [44], [45]. Likewise, conflict has been considered a social behavior that can result in a wide array of problems, with substantial negative consequences [46], [47]. However, some investigations have found that, depending on the way conflict is handled, it can significantly contribute to group success [48]. References [49] and [50] argue that we must better understand how learners manage conflict in online settings to foster dialogues toward producing better performance.

\section{INSULT INTENTIONALITY}

According to [39], most flaming studies have been limited in that they have focused on written recorded protocols of group interactions. For the context of flaming, this means looking for swearing and profanity. This approach does not adequately capture the intentionality of the players. In this case, it is possible that the hearer, in addition to the speaker, might be misinterpreting the words [51]. Similarly, some studies of interpersonal conflict [52]-[53] have analyzed transcripts as a methodology to qualify the proposed coding scheme.

A qualitative analysis of contextual discourse could reveal factors that affect players' message interpretation. Hostile language could be intended by the speaker or perceived by the hearer (or both) as humor, a common language within groups, or a well-intended behavior [54]. Some studies [38], [55], have determined that, regardless of message content and the mediation of channel richness (i.e., sound, video, online, etc.) and the cues that channel richness might express, social context is an important source of social influence. Finally, interpersonal conflict and flaming are context-dependent and 
specific to sociocultural language groups. In the context of these statements, we can presume that not all language that appears to be hostile is negative and/or undesirable for a given social interaction. In a CSCL study, [25] found that learning gains were positively correlated with insults. That is, the protocol dialogue analysis revealed that students' learning gains benefited from insults.

\section{Methods}

Thirty-two sixth-grade students from a suburban elementary school participated in this study. The students were arranged by the experimenter into pairs with a mixture of mixed-ability and homogeneous ability pairs.

The materials for the experimental were the following: a) a mathematics tutoring program covering problems on fraction addition, subtraction, multiplication, and division; and b) two extensive isomorphic tests designed for pre-test and post-test use. The pre-test and post-test versions consisted of 49 and 47 questions, respectively.

The experimental procedure spanned four school days. On the first day, a pre-test was completed individually by each student. The pre-test lasted for approximately 30 minutes with the aim of assessing how much the students knew about the subject matter. A short collaboration training manual was also provided to teach students about good collaborative dialogue. On the second and third days, the students worked together in labs for approximately 45 minutes per day. The post-test was administered on the fourth day and was separated from the third day by a weekend. This two-day lag between the last lab day and the post-test day allowed for a measure of retention. Each student performed the post-test alone. Teams remained the same throughout the experiment.

The students were encouraged to work in cooperation by offering a small prize for the teams at the end of the study based on how much they learned the subject matter and how many problems they solved correctly while working together.

This experiment allowed us to investigate students' knowledge gains based on the pre- and post-tests and to analyze the chat and the math tutoring program contributions based on students' pairs and the students alone. A total of 24 students participated in all of the experimental days. Because one student did not participate in the chat interface during two of the lab days, we reduced the sample to 23 students.

\section{RESUlts}

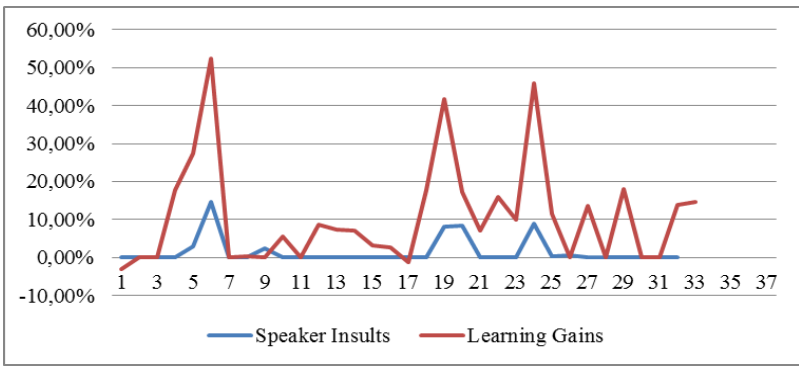

Fig. 2. Learning gains by speakers' insults. Pairs are composed by former number odd and later number even, e.g., 29-30 is a pair.

We analyzed the correlations between pre- and post-test learning gains and the frequency of each category of our coding scheme in each pair's dialogue. Interestingly, student insults were associated with significantly higher learning gains, $r=0.70, t(22)=4.53, p<.001$. In Fig. 2, we provide evidence that the four students who made learning gains of upwards of $20 \%$ were involved with insults.

\section{DISCUSSION AND CONCLUSION}

Some authors [46], [56], [40] have found that there is a particular pattern of conflict — task conflict — that is associated with higher team performance. Indeed, a CSCL environment is a task-driven environment, and thus the conflicts that occurred here should be classified as task conflict. As we observed, conflicts arose in a competitive manner. Reference [51] described a theoretical perspective for disputes that focused on the meaning and interpretations of social actors in the development and management of disputes. However, a disputing perspective is less concerned with sources or types of conflict. The findings provide evidence that the competitive player role is beneficial to the speaker. The greatest learning gains were achieved by students who adopted the competitive player role against his/her partner. In the present case, the student who did not assume a competitive role achieved below-median learning gains. Furthermore, the six students studied here who experienced lesser learning gains included student 23, who did not hold a competitive position. In the post-test, student 23 correctly answered 20 hits compared to $33,42,35,35$, and 34 correct answers from students 5, 6, 19, 20, and 24, respectively.

TABLE I: PRISONER'S DILEMMA, GAME THEORY

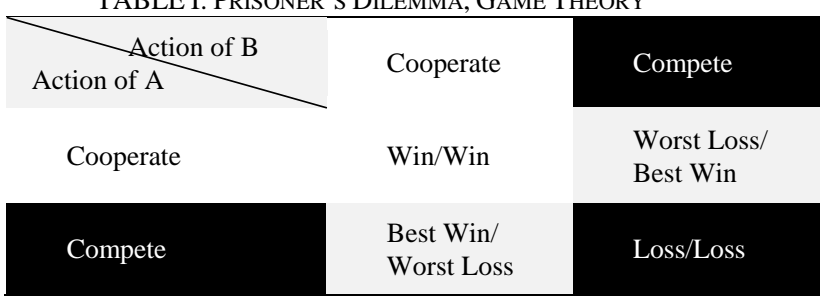

TABLE II: COLlaborative LEARNing GAIN GAME, BASED ON PRATA ET

\begin{tabular}{|c|c|c|}
\hline Speaker & Cooperate & Compete \\
\hline Cooperate & $\begin{array}{c}\text { Needs } \\
\text { Investigation }\end{array}$ & $\begin{array}{l}\text { Worst Win/ } \\
\text { Best Win* }\end{array}$ \\
\hline Compete & $\begin{array}{l}\text { Best Win/ } \\
\text { Worst Win* }\end{array}$ & $\begin{array}{l}\text { Best Win/ } \\
\text { Best Win }\end{array}$ \\
\hline
\end{tabular}

* There is little evidence to support this-further research is required.

In Table I and Table II we depict a comparison between the prisoner's dilemma and the game of collaborative learning gain. It is important to note the difference in communication means between the two scenarios. For the prisoner's dilemma, there is no communication or negotiation between parties. The prisoner has to independently decide, without reciprocal input, whether s/he cooperates with or defects from his/her partner. Finally, an arbitrator reviews the evidence and legally decides the fate of the prisoners. For the collaborative learning gain, the objective is to bidirectional negotiate a 
construction of meaning and understand the problem solving process, encouraging students to expose their beliefs by mediation.

The results of these studies foster the development of collaborative learning games in which students can play by competing with each other to learn about some subject matter. Furthermore, an intelligent agent, playing the role of a dialogue part, could persuade a student to adopt a more competitive approach towards effective learning. For instance, the design of persuasive technology is intended to change attitudes or behaviors of the users through persuasion [57]. However, most applications to date have been developed in commercial and health promotion contexts [58]. Studies in educational settings have been uncommon due to a lack of understanding of behaviors or attitudes that should be adopted by students for optimally effective learning outcomes. For instance, many studies have been based on content analysis - a wide and heterogeneous approach-or design models based on quantitative data on levels of participation [59], [60].

It appears that, in the "collaborative learning game," learners benefit from assuming a competitive role. At first glance, the competitive role does not appear to make sense. It is important, here, to understand that CSCL is a collaborative setting. That is, the students must cooperate with each other in order to construct their knowledge together. The infrastructure and methodology reflect this characteristic as well, given the encouragement of students to cooperate with the reward of a small prize. However, we looked for greater learning gains, and found that the competitive role was the best choice for effective learning, as long as they remained cooperative.

The prisoner's dilemma and the collaborative learning gain have different mediums. As [61] stated, "the medium is the message." In other words, the message is the medium itself, not the content it carries. Following McLuhan, we could presume that changing the medium would therefore change the game paradigm. The prisoner's dilemma is more like the traditional channels (e.g., TV and radio), whereas the Internet represents the collaborative learning channel. The TV channel is unidirectional, whereas the Internet is bidirectional. While on the Internet we can exchange messages, on TV we can only receive messages as a passive spectator. The paradigm of the "mass-age" 1 has long characterized our society. In the traditional classroom configuration, students are inclined to behave like the prisoner, adopting cooperative behavior in order to receive mild punishment from the arbitrator. However, this study suggests that students must compete with each other by exposing and exchanging their ideas. This, presumably, facilitates cognitive development in a CSCL environment.

According to our study, for the collaborative learning game, when both students compete in a CSCL environment, both win. When one competes and the other does not, the competitor wins. Reference [26] also observed positive learning for the cognitive behavior of competition. According to [5], it is inconceivable to dissociate cognitive tasks from social tasks because all cognitive tasks have a

\footnotetext{
${ }^{1}$ McLuhan punned on the word "message."
}

social component. For future work, we must extend our investigation to better understand the role of cooperation in a CSCL environment. In the current study, in the case of pair 23-24's conversation, it would be advisable for the agent to intervene in the dialogue to suggest that student 23 change his/her passive position to a more competitive one. However, further research using CSCL with students from others cultures and countries would be worthwhile.

\section{ACKNOWLEDGMENT}

D. P. would like to thank Ryan Baker and Carolyn Rose for their support.

\section{REFERENCES}

[1] P. Dillenbourg, M. Baker, A. Blaye, and C. O’Malley, “The evolution of research on collaborative learning," in E. Spada and P. Reiman (Eds.), Learning in Humans and Machine: Towards an Interdisciplinary Learning Science, Oxford, UK: Elsevier. 1995, pp. 189-211.

[2] B. K. Nastasi and D. H. Clements, "Social-cognitive behaviors and higher-order thinking in educational computer environments," Learning and Instruction, vol. 2, pp. 215-238, 1992.

[3] J. Roschelle and S. D. Teasley, "The construction of shared knowledge in collaborative problem solving," in C. E. O'Malley (Ed.), Computer-Supported Collaborative Learning, Berlin, Germany: Springer-Verlag, 1995, pp. 69-197.

[4] A. M. O'Donnell and D. F. Dansereau, "Scripted cooperation in student dyads: A method for analyzing and enhancing academic learning and performance," in R. Hertz-Lazarowitz and N. Miller (Eds.), Interaction in Cooperative Groups. The Theoretical Anatomy of Group Learning, pp. 120-141, New York, NY: Cambridge University Press, 1992.

[5] A. N. Perret-Clermont, "What is it that develops?" Cognition and Instruction, vol. 11, pp. 197-205, 1993

[6] C. P. Rose, Y. C. Wang, Y. Cui, J. Arguello, F. Fischer, A. Weinberger, and K. Stegmann, "Analyzing collaborative learning processes automatically: Exploiting the advances of computational linguistics in computer-supported collaborative learning," International Journal of Computer Supported Collaborative Learning, vol. 3, no. 3, pp. 237-271, 2008.

[7] D. R. Lyman and R. Selman, "Peer conflict in pair therapy: Clinical and developmental analyses," in M. Berkowitz (Ed.), New Directions in Child Development: Peer Conflict and Psychological Growth, San Francisco, CA: Jossey Bass, 1985.

[8] V. U. Druskat, and C. D. Kayes, "Learning versus performance in short-term project teams," Small Group Research, vol. 31, pp. 328-353, 2000 .

[9] D. R. Bacon, K. A. Stewart, and W. S. Silver, "Lessons from the best and worst student team experiences: How a teacher can make the difference," Journal of Management Education, vol. 23, no. 5, pp. 467-488, 1999.

[10] D. W. Johnson and R. T. Johnson, "Cooperation and the use of technology," in D. H. Johanssen (2nd ed.), Handbook of Research on Educational Communications and Technology, pp. 785-811, Mahwah, NJ: Lawrence Erlbaum Associates, 2004.

[11] K. Kreijns, P. A. Kirschner, and W. Jochems, "Identifying the pitfalls for social interaction in computer-supported collaborative learning environments: A review of the research," Computers in Human Behavior, vol. 19, pp. 335-353, 2003.

[12] S. Liaw and H. Huang, "Enhancing interactivity in web-based instruction: A review of the literature," Educational Technology, vol. 40, no. 3, pp. 41-45, 2000.

[13] D. W. Johnson and R. T. Johnson, Learning Together and Alone: Cooperative, Competitive, and Individualistic Learning, 5th Ed., Boston, MA: Allyn and Bacon, 1999.

[14] D. Boud, R. Cohen, and J. Sampson, "Peer learning and assessment," Assessment and Evaluation in Higher Education, vol. 24, pp. 413-426, 1999.

[15] K. Kreijns and P. A. Kirschner, "Determining sociability, social space and social presence in (a) synchronous collaborating teams," Cyberpsychology and Behavior, vol. 7, pp. 155-172, 2004.

[16] L. Waghorn and E. V. Sullivan, "The exploration of transition rules in conservation of quantity (substance) using film mediated modeling,' Acta Psychologica, vol. 32, pp. 65-80, 1970. 
[17] T. L. Rosenthal and B. J. Zimmerman, "Modeling by exemplification and instruction in training conservation," Developmental Psychology, vol. 6, pp. 392-401, 1972.

[18] I. W. Silverman and E. Geiringer, "Dyadic interaction and conservation induction: A test of Piaget's equilibration model," Child Development, vol. 44, pp. 815-820, 1973.

[19] S. A. Miller and C. A. Brownell, "Peers, persuasion, and piaget: Dyadic interaction between conservers and nonconservers," Child Development, vol. 46, pp. 992-997, 1975.

[20] F. B. Murray, G. Ames, and G. Botvin, "The acquisition of conservation through cognitive dissonance," Journal of Educational Psychology, vol. 69, pp. 519-527, 1977.

[21] G. J. Ames and F. Murray, "When two wrongs make a right: Promoting cognitive change by social conflict," Developmental Psychology, vol. 18, no. 6, pp.892-895, 1982.

[22] J. Piaget, "The role of action in the development of thinking," in W. F. Overton and J. M. Gallagher (Eds.), Advances in Research and Theory, New York, NY: Plenum Press, 1977.

[23] W. F. Arsenio, "A. lover, a. emotions, conflicts, and aggression during preschoolers' free play," British Journal of Developmental Psychology, vol. 15, pp. 531-542, 1977.

[24] D. W. Shantz, "Conflict, aggression, and peer status: An observational study," Child Development, vol. 57, pp. 1322-1332, 1986.

[25] D. N. Prata, R. S. J. D. Baker et al., "Detecting and understanding the impact of cognitive and interpersonal conflict in computer supported collaborative learning environments," in Proc. Educational Data Mining, pp. 131-140, 2009.

[26] D. Prata, P. Letouze, E. Costa, M. Prata, and G. Brito, "Dialogue analysis in collaborative learning," International Journal of e-Education, e-Business, e-Management and e-Learning, vol. 2, no. 5, pp. 365-372, 2012.

[27] J. L. Austin, How to Do Things with Words, Oxford: Oxford University Press, England, 1962.

[28] N. R. Jennings, P. Faratin, A. R. Lomuscio, S. Parsons, C. Sierra, and M. Wooldridge, "Automated negotiation: Prospects, methods and challenges," International Journal of Group Decision and negotiation, vol. 10, no. 2, pp. 199-215, 2001.

[29] E. Bellucci and J. Zeleznikow, "A comparative study of negotiation decision support systems," in Proc. the Thirty-First Annual Hawaii International Conference on System Sciences, vol. 1, pp. 254-263, January, 1988.

[30] J. F. Nash, "Two-person cooperative games," Econometrica, vol. 21, pp. 128-140, 1953.

[31] D. Walton and A. R. Lodder, "What role can rational argument play in $\mathrm{ADR}$ and online dispute resolution?" Second International ADR Workshop, pp. 69-76, Tilburg: Wolf Legal Publishers, 2005.

[32] J. Burton, The Environment of Conflict, New York, NY: Saint Martins Press, 1990.

[33] V. J. Dubrovsky, S. Kiesler, and B. N. Sethna, "The equalization phenomenon: Status effects in computer-mediated and face-to-face decision-making groups," Human Computer Interaction, vol. 6, pp. 119-146, 1991.

[34] J. M. Kayany, "Contexts of uninhibited online behavior: Flaming in social newsgroups on Usenet," Journal of the American Society for Information Science, vol. 49, pp. 1135-1141, 1998.

[35] R. Spears and M. Lea, "Social influence and the influence of the "social" in computer-mediated communication," in M. Lea (ed.), Contexts of Computer Mediated Communication, pp. 30-65, London, UK: Harvester-Wheatsheaf, 1992.

[36] J. Z. Rubin, D. G. Pruitt, and S. H. Kim, Social conflict. Escalation, Stalemate, and Settlement (2nd Ed.), New York, NY: McGraw-Hill, Inc. 1994.

[37] D. J. Canary, W. R. Cupach, and S. J. Messman, Relationship Conflict, London, UK: Sage Publications, 1995.

[38] M. Lea, T. O'Shea, P. Fung, and R. Spears, “Flaming' in computer-mediated communication: Observations, explanations, implications," in M. Lea (Ed.), Contexts of Computer-Mediated Communication, pp. 89-112, New York, NY: Harvester-Wheatsheaf, 1992.

[39] P. B. O’Sullivan and A. J. Flanagin, "Reconceptualizing 'flaming' and other problematic messages," New Media and Society, vol. 5, no. 1, pp. 69-94, 2003.

[40] K. A. Jehn and E. Mannix, "The dynamic nature of conflict: A longitudinal study of intragroup conflict and group performance," Academy of Management Journal, vol. 44, pp. 238-251, 2001.

[41] M. Alonzo and M. Aiken, "Flaming in electronic," Decision Support Systems, vol. 36, pp. 205-217, 2004.
[42] R. L. Daft and R. H. Lengel, "Information richness: A new approach to managerial behavior and organization design," in B. M. Staw and L. L. Cummings (Eds.), Research in Organizational Behavior, vol. 6, pp. 191-233, Greenwich, CT: JAI Press, 1984.

[43] S. Kiesler, J. Siegel, and T. W. McGuire, "Social psychological aspects of computer-mediated communication," American Psychologist, vol. 39, pp. 1123-1134, 1984.

[44] P. A. Thompsen and D. A. Fougler, "Effects of pictographs and quoting on flaming in electronic mail," Computers in Human Behavior, vol. 12 , pp. 225-243, 1996.

[45] G. C. Colomb and J. A. Simutis, "Visible conversation and academic inquiry: CMC in a culturally diverse classroom," in S. C. Herring (Ed.), Computer-Mediated Communication: Linguistic, Social and Cross-Cultural Perspectives, pp. 203-222, Amsterdam, Netherlands: J. Benjamins, 1996.

[46] K. A. Jehn, "Enhancing effectiveness: An investigation of advantages and disadvantages of value-based intragroup conflict," International Journal of Conflict Management, vol. 5, pp. 223-238, 1994.

[47] O. J. Bartos and P. Wehr, Using Conflict Theory, Cambridge, UK: Cambridge University Press, 2002.

[48] S. Paul, S. Priya, S. Imad, and P. P. Mykytyna, "Impact of heterogeneity and collaborative conflict management style on the performance of synchronous global virtual teams," Information and Management, vol. 41, pp. 303-321, 2004.

[49] K. Carabajal, D. LaPointe, and C. N. Gunawardena, "Group development in online learning communities," in M. Moore and W. Anderson (Eds.), Handbook of Distance Education, pp. 217-234, Nahwah, NJ: Erlbaum Associates Inc., 2003.

[50] C. R. Graham, Understanding and Facilitating Computer-Mediated Teamwork: A Study of How Norms Develop in Online Learning Teams Indiana University, Bloomington, IN. 2002.

[51] J. Picard, "Researching social conflict in collaborative groups," presented at the Proceedings of the Fifth International Conference on Networked Learning, Lancaster, UK. 2006.

[52] E. V. Hobman, P. Bordia, B. Irmer, and A. Chang, "The expression of conflict in computer-mediated and face-to-face groups," Small Group Research, vol. 33, no. 4, pp. 439-465, 2002.

[53] K. J. Behfar, E. A. Mannix, R. S. Peterson, and W. M. Trochim, "Conflict in small groups: The meaning and consequences of process conflict," Small Group Research, vol. 42, no. 2, pp. 127-176, 2004.

[54] C. D. Mortensen, Miscommunication, Thousand Oaks, CA: Sage. 1997.

[55] T. Postmes, R. Spears, and M. Lea, "Breaching or building social boundaries: SIDE-Effects of computer-mediated communication," Communication Research, vol. 25, no. 6, pp. 689-715, 1998.

[56] L. A. DeChurch and M. A. Marks, "Maximizing the benefits of task conflict: The role of conflict management," The International Journal of Conflict Management, vol. 12, no. 1, pp. 4-33, 2001.

[57] B. J. Fogg, Persuasive Technology: Using Computers to Change What We Think and Do, San Francisco, CA: Morgan Kaufmann, 2003.

[58] J. Mintz and M. Aagaard, "The application of persuasive technology to educational settings," Educational Technology Research and Development, vol. 60, no. 3, pp. 483-499, 2012.

[59] F. Henri, "Computer conferencing and content analysis," in A. R. Kaye (Ed.), Collaborative Learning through Computer Conferencing. The Najadan Papers, pp. 117-136, London, UK: Springer-Verlag, 1992.

[60] A. Soller, "Supporting social interaction in an intelligent collaborative learning system," International Journal of Artificial Intelligence in Education, vol. 12, no. 40-62, 2001.

[61] M. McLuhan, Understanding Media: The Extensions of Man, New York: McGraw-Hill Book Company, 1964.

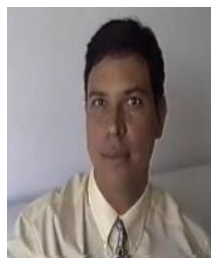

David Prata was born in Goiânia, Brazil on 18th September, 1965. Dr. Prata completed his bachelor of computer science in 1992. Later on, he went to complete his specializing in academician. He worked as a system analyst to Tocantins Government, being in charge for the accountability and financial systems. Later, he successfully completed his master degree in computer science from Campina Grande Federal University, with application research in education in 2000 year. He coordinates graduate and undergraduate courses in computer science at Alagoas Faculty in Maceio, Brazil. He was allotted to Federal University of Alagoas in 2006. Then, he moved to Federal University of Tocantins. His doctoral was developed in part at Carnegie Mellon University, USA, completed in 2008. He is currently coordinating a master degree in computational model. His research interests are education and ecosystems. 
Patrick Letouze is with the Computer Science Department at the Federal University of Tocantins, and currently he is the director of the Software Development Nucleus - NDS.

Stefano A. Cerri was born in Parma, Italy, on February 14, 1947. Stefano A. Cerri a professor in informatics since 1985, whose main areas of research include artificial intelligence, human-computer interaction, human learning.

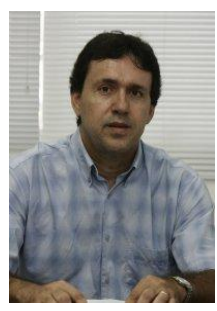

Evandro de Barros Costa completed his bachelor of computer science in 1988 at Federal University of Paraíba. He took his doctoral in 1997. Currently he is an associated professor at Federal University of Alagoas, allotted at Computation Institute. He has experience in computation field highlighted in artificial intelligence and software engineering based on agents. He acts mainly with multiagent systems, intelligent tutoring systems, knowledge representation and semantic Web, intelligent agents and informatics in education. He was in charge in many projects funded by government agencies. He has been reviser for periodicals and participated in committees from national and international programs. 